\title{
Financing and cost-effectiveness analysis of public-private partnerships: provision of tuberculosis treatment in South Africa Edina Sinanovic*1 and Lilani Kumaranayake ${ }^{2}$
}

\author{
Address: ${ }^{1}$ Health Economics Unit, School of Public Health \& Family Medicine, Faculty of Health Sciences, University of Cape Town, Anzio Rd, \\ 7925 Observatory, South Africa and 2Department of Public Health and Policy, London School of Hygiene and Tropical Medicine. Keppel St., \\ London, WC1E 7HT, UK \\ Email: Edina Sinanovic* - edina@heu.uct.ac.za; Lilani Kumaranayake - lilani.kumaranayanke@lshtm.ac.uk \\ * Corresponding author
}

Published: 06 June 2006

Cost Effectiveness and Resource Allocation 2006, 4:1 I doi:10.1 186/1478-7547-4-1I

This article is available from: http://www.resource-allocation.com/content/4/I/II

(c) 2006 Sinanovic and Kumaranayake; licensee BioMed Central Ltd.

This is an Open Access article distributed under the terms of the Creative Commons Attribution License (http://creativecommons.org/licenses/by/2.0), which permits unrestricted use, distribution, and reproduction in any medium, provided the original work is properly cited.
Received: 20 September 2005

Accepted: 06 June 2006

\begin{abstract}
Background: Public-private partnerships (PPP) could be effective in scaling up services. We estimated cost and cost-effectiveness of different PPP arrangements in the provision of tuberculosis (TB) treatment, and the financing required for the different models from the perspective of the provincial TB programme, provider, and the patient.

Methods: Two different models of TB provider partnerships are evaluated, relative to sole public provision: public-private workplace (PWP) and public-private non-government (PNP). Cost and effectiveness data were collected at six sites providing directly observed treatment (DOT). Effectiveness for a 12-month cohort of new sputum positive patients was measured using cure and treatment success rates. Provider and patient costs were estimated, and analysed according to sources of financing. Cost-effectiveness is estimated from the perspective of the provider, patient and society in terms of the cost per TB case cured and cost per case successfully treated.

Results: Cost per case cured was significantly lower in PNP (US \$354-446), and comparable between PWP (US \$788-979) and public sites (US \$700-1000). PPP models could significantly reduce costs to the patient by $64-100 \%$. Relative to pure public sector provision and financing, expansion of PPPs could reduce government financing required per TB patient treated from $\$ 609-$ 690 to $\$ 130-139$ in PNP and \$36-46 in PWP.

Conclusion: There is a strong economic case for expanding PPP in TB treatment and potentially for other types of health services. Where PPPs are tailored to target groups and supported by the public sector, scaling up of effective services could occur at much lower cost than solely relying on public sector models.
\end{abstract}

\section{Background}

In line with the global tuberculosis-related Millennium Development Goals to halt and begin to reverse the incidence of tuberculosis (TB) by 2015, the Stop TB Partnership set targets to halve TB prevalence and death by 2015 [1]. To achieve and sustain these targets, a variety of pro- vision and financing models needs to be considered in developing country health systems. Even with strengthened public health provision, the resulting outcomes may not be as expected. Recent analysis of tuberculosis (TB) control goals found that despite broad coverage through public programmes, proportionate increases in case- 
detection rates were not achieved. Projections suggest that at current rates, even if there were $100 \%$ global coverage by DOTS - the internationally recommended control strategy for TB, only half of new infectious cases would be detected [2]. Key reasons for this are that patients do not have access to public health facilities or seek care from providers not linked to national programmes or the public health system - such as private doctors working in their own facilities or for employer health services [2,3]. Private TB treatment provision has been characterised by limited notification of cases from the private sector, inappropriate drug regimens, and unknown treatment outcomes $[4,5]$.

Public sector collaboration with private providers can range from provision of information and education to formal public-private partnerships (PPPs) with small-scale contracting of service components or larger-scale sharing of health care provision and financing [6-9]. PPPs seek to complement rather than substitute for public health services. Partnerships with traditional healers, communitybased organisations and private practitioners can provide a number of benefits, including increased numbers of people receiving services, leveraging of additional resources, improved private provider technical capacity, and adherence to national protocols helping to minimise drug resistance [8].

South Africa is one of several countries where partnerships between the public and private sectors have been recognised as a policy objective [10], with the National Treasury developing its own guidelines for PPPs related to design, procurement and implementation [11]. In response to the dual TB/HIV epidemic, the national tuberculosis programme has began to collaborate with different private providers in the provision of $\mathrm{TB}$ treatment. This study explores cost and cost-effectiveness of different existing PPP arrangements for TB DOTS provision. The financing required for the different models from the perspective of the provincial $\mathrm{TB}$ programme, provider, and the patient are also estimated. Previous economic studies have shown a reduction in costs and improvement in costeffectiveness of DOTS through decentralisation and strengthened community-based care [12-18]. Besides the study on the cost-effectiveness of two public-private mix pilot projects in India [19] to-date there have been no published studies on the cost-effectiveness of PPP involving private providers for the purposes of $\mathrm{TB}$ diagnosis and treatment, nor studies on the public sector financing requirements for any type of PPP - the latter is critical if considering the potential scale-up or replication of PPPs.

\section{Methods \\ Background}

The South African National TB Control Programme adopted the DOTS strategy in 1996. South Africa has achieved the WHO target rate of $70 \%$ case detection, but despite DOTS population coverage of $93 \%$ in 2004, the treatment success rate of $67 \%$ [20] remains well below the WHO target of $85 \%$. The TB epidemic is fuelled by the HIV epidemic with over 6.5 million people infected with HIV in South Africa in 2002 [21], and $60 \%$ of TB adult patients also HIV positive [20].

\section{Models of provision}

Three different models of DOT provision were evaluated for different target groups: purely public, public-private workplace partnership (PWP), and public-non-governmental organisation partnership (PNP). The justification for using three models as case studies was that they complement each other by demonstrating a range of models of provision, all of which may be relevant in particular settings. In the public model, patients are diagnosed and treated in public clinics, with direct observation undertaken in the public health facilities by health workers following national treatment guidelines [22]. The PWP model represents a partnership between provincial TB programmes and mining companies where the employer's occupational health services are either reimbursed per patient day or receive free drugs for each TB patient treated in their clinics. The type of reimbursement depends on the provincial regulations. Mining companies were selected, as there is a long history of TB treatment in the industry. The PNP model is a partnership between provincial TB programmes and non-governmental organisations (NGOs) providing community-based DOT in which these NGOs are paid a monthly sum per patient to manage community-based $\mathrm{TB}$ programmes. In this model, patients are diagnosed and monitored in public clinics for the first 10 days. Subsequent treatment is directly observed by community health worker 'treatment supporters' in the community. In addition to the funding from the provincial TB control programme, these NGOs receive funding from other sources such as charities and donors. In return for payments from provincial TB programmes both private partners are required to follow national treatment guidelines, complete and submit standardised quarterly reports to district $\mathrm{TB}$ coordinators, and liaise with district public health facilities.

\section{Site selection}

For each type of provision model, 2 sites were selected (Table 1). Sites were identified using key informant interviews with provincial TB programme officials, and then selected by purposive sampling according to their availability, urban-rural locations, different reimbursement mechanisms, and willingness to participate in the study. Differentials among sites in terms of TB incidence and HIV prevalence reflected the variation in target populations reached by the PPPs. 


\begin{tabular}{|c|c|c|c|c|c|c|}
\hline \multirow[t]{2}{*}{ Model/Site } & \multicolumn{2}{|c|}{ PWP model } & \multicolumn{2}{|c|}{ PNP model } & \multicolumn{2}{|c|}{ Purely public model } \\
\hline & Site I $(N=95)$ & Site $2(N=423)$ & Site $3(N=355)$ & Site $4(N=50)$ & Site $5(N=85)$ & Site $6(N=174)$ \\
\hline Type of provision & Private workplace & Private workplace & Private non-governmental & Private non-governmental & Public & Public \\
\hline Type of facility & Occupational health clinic & Occupational health clinic & $\begin{array}{l}\text { Clinic working closely with a } \\
\text { local NGO }\end{array}$ & $\begin{array}{l}\text { Clinic working closely with a } \\
\text { local NGO }\end{array}$ & Health clinic & Health clinic \\
\hline Location (Province) & $\begin{array}{l}\text { Near large rural town in } \\
\text { North West }\end{array}$ & $\begin{array}{l}\text { Near small rural town in Free } \\
\text { State }\end{array}$ & $\begin{array}{l}\text { Urban informal settlement in } \\
\text { Western Cape }\end{array}$ & $\begin{array}{l}\text { Rural informal settlement in } \\
\text { Western Cape }\end{array}$ & $\begin{array}{l}\text { Small rural town in Western } \\
\text { Cape }\end{array}$ & $\begin{array}{l}\text { Urban city area in Western } \\
\text { Cape }\end{array}$ \\
\hline Population served & $\begin{array}{l}\text { Low income workers, } \\
\text { predominantly male }\end{array}$ & $\begin{array}{l}\text { Low income workers, } \\
\text { predominantly male }\end{array}$ & $\begin{array}{l}\text { Low income residents, male } \\
\text { and female adults, high } \\
\text { unemployment }\end{array}$ & $\begin{array}{l}\text { Low income residents, male } \\
\text { and female adults, high } \\
\text { unemployment }\end{array}$ & $\begin{array}{l}\text { Low income residents, male } \\
\text { and female adults, high } \\
\text { unemployment }\end{array}$ & $\begin{array}{l}\text { Low income residents, male } \\
\text { and female adults, high } \\
\text { unemployment }\end{array}$ \\
\hline $\begin{array}{l}\text { TB incidence per } 100000 \\
\text { population* }\end{array}$ & 1073 & 3012 & 439 & 149 & 169 & 176 \\
\hline $\begin{array}{l}\text { Approximated HIV } \\
\text { prevalence in the study } \\
\text { population** }\end{array}$ & (approx) 44\% & (approx) 48\% & (approx) 39\% & (approx) 36\% & (approx) 29\% & (approx) 23\% \\
\hline Overall TB service range ${ }^{\dagger}$ & $\begin{array}{l}\text { Surveillance for TB, diagnosis } \\
\text { and treatment }\end{array}$ & $\begin{array}{l}\text { Surveillance for TB, diagnosis } \\
\text { and treatment }\end{array}$ & $\begin{array}{l}\text { Diagnosis, treatment, and } \\
\text { social support }\end{array}$ & $\begin{array}{l}\text { Diagnosis, treatment, and } \\
\text { social support }\end{array}$ & Diagnosis and treatment & Diagnosis and treatment \\
\hline Case finding & $\begin{array}{l}\text { Annual radiological screening; } \\
\text { passive, and contact tracing }\end{array}$ & $\begin{array}{l}\text { Annual radiological screening; } \\
\text { passive, and contact tracing }\end{array}$ & Passive & Passive & Passive & Passive \\
\hline Diagnosis & $\begin{array}{l}\text { Sputum smears; all patients } \\
\text { with suspected pulmonary TB } \\
\text { should have I sputum } \\
\text { specimen submitted for } \\
\text { culture }\end{array}$ & $\begin{array}{l}\text { Sputum smears; all patients } \\
\text { with suspected pulmonary TB } \\
\text { should have I sputum } \\
\text { specimen submitted for } \\
\text { culture }\end{array}$ & $\begin{array}{l}\text { Sputum smears; I sputum for } \\
\text { culture if smear negative at } \\
\text { diagnosis and unresponsive to } \\
\text { a course of antibiotics }\end{array}$ & $\begin{array}{l}\text { Sputum smears; I sputum for } \\
\text { culture if smear negative at } \\
\text { diagnosis and unresponsive to } \\
\text { a course of antibiotics }\end{array}$ & $\begin{array}{l}\text { Sputum smears; I sputum for } \\
\text { culture if smear negative at } \\
\text { diagnosis and unresponsive to } \\
\text { a course of antibiotics }\end{array}$ & $\begin{array}{l}\text { Sputum smears; I sputum for } \\
\text { culture if smear negative at } \\
\text { diagnosis and unresponsive to } \\
\text { a course of antibiotics }\end{array}$ \\
\hline DOT system in place & $\begin{array}{l}\text { Hospitalisation for the first } 7 \\
\text { days followed by DOT by } \\
\text { nurses in the occupational } \\
\text { clinics }\end{array}$ & $\begin{array}{l}\text { DOT by nurses in the } \\
\text { occupational health clinics }\end{array}$ & $\begin{array}{l}\text { DOT by nurses in the public } \\
\text { clinic for the first } 10 \text { days } \\
\text { followed by DOT by } \\
\text { 'treatment supporters' in the } \\
\text { community }\end{array}$ & $\begin{array}{l}\text { DOT by nurses in the public } \\
\text { clinic for the first } 10 \text { days } \\
\text { followed by DOT by } \\
\text { 'treatment supporters' in the } \\
\text { community }\end{array}$ & $\begin{array}{l}\text { DOT by nurses in the public } \\
\text { clinic }\end{array}$ & $\begin{array}{l}\text { DOT by nurses in the public } \\
\text { clinic }\end{array}$ \\
\hline
\end{tabular}

* Source for TB prevalence: providers' annual reports.

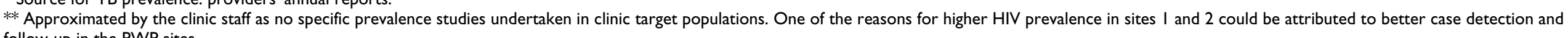
follow-up in the PWP sites.

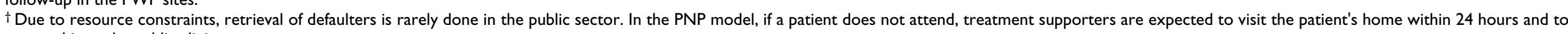
report this to the public clinic.

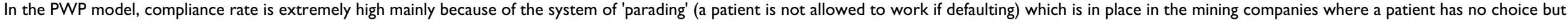
adhere to the treatment.

\section{Procedure}

Data collection was undertaken between March 2002 and February 2003. Written consent was obtained from all the study providers. A verbal patient consent was also sought. Ethical approval was obtained from both the University of Cape Town and London School of Hygiene and Tropical Medicine ethical committees.

\section{Cost and cost-effectiveness}

The cost analysis was retrospectively undertaken from a provider perspective and a societal perspective. Costs were collected for a 12-month period in each facility between 2000 and 2001. Average, rather than marginal, economic costs were assessed, which are more relevant for national policy [23]. An ingredients-based costing methodology was used where quantities of resources were multiplied by their respective prices to obtain total costs. Capital costs were annualised using life expectancies of 30 years for buildings,
10 years for equipment, 5 years for vehicles and training, and the standard discount rate of $3 \%[24]$

Methods used for measuring, identifying and valuing the costs of TB treatment are given in Table 2. The average cost of managing a new smear-positive patient from diagnosis to completion of treatment for each site was calculated by multiplying the average cost of each treatment component by the number of times the cost was incurred according to the site-specific clinic protocols.

Patient costs (time and travel costs) were estimated using a retrospective structured patient interview. A sample of 20 randomly chosen patients in each site was used due to time constraints. No patients were interviewed in the PWP model as DOT is provided in the workplace. Patient costs of seeking care prior to the facility where they were inter- 
Table 2: Methods used for measuring, identifying and valuing the costs of TB treatment

\begin{tabular}{|c|c|c|c|c|c|}
\hline \multirow[t]{2}{*}{ Type of cost } & \multirow{2}{*}{$\begin{array}{c}\text { Identification } \\
\text { Categories }\end{array}$} & \multicolumn{2}{|c|}{ Measurement } & \multicolumn{2}{|c|}{ Valuation } \\
\hline & & Costing method & Sources of data & Valuation method & Sources of data \\
\hline \multicolumn{6}{|l|}{ Recurrent } \\
\hline Personnel & $\begin{array}{l}\text { Administration and } \\
\text { management, clinical } \\
\text { staff (doctors, nurses, } \\
\text { lay workers*), and } \\
\text { support staff } \\
\text { (cleaning) }\end{array}$ & $\begin{array}{l}\text { Percentage of time } \\
\text { spent on different } \\
\text { activities }\end{array}$ & $\begin{array}{l}\text { Observation** and } \\
\text { semi-structured } \\
\text { interviews with } \\
\text { providers }\end{array}$ & $\begin{array}{l}\text { Total remuneration } \\
\text { package costs }\end{array}$ & $\begin{array}{l}\text { Provider expenditure } \\
\text { reports }\end{array}$ \\
\hline Supplies & $\begin{array}{l}\text { Sputum and culture } \\
\text { tests, } x \text {-rays and drugs }\end{array}$ & Quantity consumed & Patient records & Market prices & $\begin{array}{l}\text { Provincial and private } \\
\text { laboratories and } \\
\text { pharmacy price lists }\end{array}$ \\
\hline $\begin{array}{l}\text { Vehicle operating and } \\
\text { maintenance }\end{array}$ & Vehicle running costs & $\begin{array}{l}\text { Number of kilometres } \\
\text { travelled }\end{array}$ & $\begin{array}{l}\text { Vehicle logbook, } \\
\text { interview with clinic } \\
\text { manager }\end{array}$ & $\begin{array}{l}\text { Actual expenditure on } \\
\text { fuel, oil and } \\
\text { maintenance }\end{array}$ & $\begin{array}{l}\text { Automobile } \\
\text { Association rates }\end{array}$ \\
\hline $\begin{array}{l}\text { Building operating and } \\
\text { maintenance }\end{array}$ & $\begin{array}{l}\text { Overheads (water, } \\
\text { electricity, telephone, } \\
\text { fax, stationeries etc) }\end{array}$ & $\begin{array}{l}\text { Proportion of total } \\
\text { visits for which TB } \\
\text { patients accounted }\end{array}$ & $\begin{array}{l}\text { Actual costs from } \\
\text { facility records, } \\
\text { interview with clinic } \\
\text { manager }\end{array}$ & Actual expenditure & $\begin{array}{l}\text { Provider expenditure } \\
\text { reports }\end{array}$ \\
\hline \multicolumn{6}{|l|}{ Capital ${ }^{\dagger}$} \\
\hline Buildings & $\begin{array}{l}\text { Offices, clinics and } \\
\text { hospitals }\end{array}$ & $\begin{array}{l}\text { Proportion of total } \\
\text { visits for which TB } \\
\text { patients accounted }\end{array}$ & $\begin{array}{l}\text { Interview with clinic } \\
\text { manager }\end{array}$ & Replacement prices & $\begin{array}{l}\text { CSIR Building and } \\
\text { Construction } \\
\text { Technology }\end{array}$ \\
\hline Equipment & $\begin{array}{l}\text { Furniture, medical and } \\
\text { non-medical } \\
\text { equipment }\end{array}$ & $\begin{array}{l}\text { Proportion of total } \\
\text { visits for which TB } \\
\text { patients accounted) }\end{array}$ & $\begin{array}{l}\text { Interview with clinic } \\
\text { manager }\end{array}$ & Replacement prices & Local manufacturers \\
\hline Vehicles & $\begin{array}{l}\text { Vehicles used for TB } \\
\text { patients }\end{array}$ & $\begin{array}{l}\text { Vehicle utilisation ( } \mathrm{km} \\
\text { travelled) }\end{array}$ & $\begin{array}{l}\text { Vehicle log book, } \\
\text { interview with clinic } \\
\text { manager }\end{array}$ & Replacement prices & Local car dealers \\
\hline Training & $\begin{array}{l}\text { Community } \\
\text { "treatment } \\
\text { supporters" training }\end{array}$ & $\begin{array}{l}\text { Number of treatment } \\
\text { supporters trained }\end{array}$ & $\begin{array}{l}\text { Actual costs from } \\
\text { NGO records }\end{array}$ & Actual expenditure & $\begin{array}{l}\text { Provider expenditure } \\
\text { reports }\end{array}$ \\
\hline
\end{tabular}

\footnotetext{
* Average cost 'treatment supporter' visits was based on the NGO payment per visit.

** Observation was used to determine clinic staff time spent on each type of visit made by adults. No variations in terms of the HIV status and gender of the patient were done.

$\dagger$ Life expectancies of buildings were 30 years, equipment 10 years, vehicles and training 5 years, and the standard discount rate of $3 \%$ (24).
}

viewed were excluded from the analysis. Time costs were converted to a monetary value based on the average income reported by the patients interviewed [24]. Diagnosis and treatment of TB are free of charge to patients in all study sites.

To calculate the effectiveness measures, the cohort of all new smear-positive TB patients who started treatment during the 12-month costing period was followed to obtain the treatment outcomes. New smear-positive cases were selected because they are the most infectious cases, and therefore have the highest public health importance; the South African DOTS strategy focuses primarily on improving the cure rate among new patients; and data on these cases were readily obtainable. The cost-effectiveness ratio was calculated for each model of provision by dividing cost by the unit of effect and compared with each other. As these partnership models use resources from three different sources (provider, patient and govern- ment), both a provider and societal perspective is adopted for the cost-effectiveness analysis.

\section{Sensitivity analyses}

To reflect the uncertainty inherent in the analysis, four univariate sensitivity analyses were performed: using alternative assumptions regarding provider costs (reduction of $50 \%$ of value of staff time in baseline analysis due to a possibility that staff time could have been overestimated); using alternative assumptions regarding patient costs (limits of $95 \%$ confidence interval); variation in discount rates (3\% below and above the rate used in baseline analysis); and adjusting effectiveness data by the death rate in order to explore the importance of different HIV prevalence across sites. Effectiveness was recalculated by adjusting the total number of patients in the cohort by the total number of deaths in the same cohort. Different assumptions about provider and patient costs were examined because they constitute the major costs. A multivari- 
ate sensitivity analysis, where estimates of provider cost and effectiveness adjusted by the death rate are varied at the same time, was also performed.

\section{Results}

\section{Average cost per patient treated}

The cost per TB patient treated varied across the models of treatment provision (Table 3 ) with the highest costs for the PWP models (US\$ 654-744) reflecting different protocols related to hospitalisation (site 1 ) and procurement of drugs. In site 2 , the only site without public financing of drugs, $52 \%$ of the entire treatment cost was drugs. The PNP model

Table 3: Average provider costs (\% of total), mean patient costs $(95 \%$ confidence interval) and financing (\% of total), US $\$ *$

\begin{tabular}{|c|c|c|c|c|c|c|}
\hline \multirow[t]{2}{*}{ Average provider costs } & \multicolumn{2}{|c|}{ PWP model } & \multicolumn{2}{|c|}{ PNP model } & \multicolumn{2}{|c|}{ Purely public model } \\
\hline & $\begin{array}{r}\text { Site I } \\
N=95\end{array}$ & $\begin{array}{r}\text { Site } 2 \\
N=423\end{array}$ & $\begin{array}{r}\text { Site } 3 \\
N=355\end{array}$ & $\begin{array}{r}\text { Site } 4 \\
N=50\end{array}$ & $\begin{array}{r}\text { Site } 5 \\
N=85\end{array}$ & $\begin{array}{r}\text { Site } 6 \\
N=174\end{array}$ \\
\hline Hospital stay** & $220(34 \%)$ & N.A.t† & N.A. & N.A. & N.A. & N.A. \\
\hline $\begin{array}{l}\text { Health clinic visits for } \\
\text { monitoring** }\end{array}$ & 14 (2.1\%) & $18(2.4 \%)$ & $23(9 \%)$ & $24(9 \%)$ & $19(4 \%)$ & $20(3 \%)$ \\
\hline Health clinic visits for DOT** & $334(51 \%)$ & $301(40 \%)$ & $36(14 \%)$ & $39(16 \%)$ & $426(84 \%)$ & $485(85 \%)$ \\
\hline $\begin{array}{l}\text { Visits to 'treatment } \\
\text { supporters'** }\end{array}$ & N.A. & N.A. & $55(22 \%)$ & $55(22 \%)$ & N.A. & N.A. \\
\hline Sputum smears ${ }^{\dagger}$ & $12(1.8 \%)$ & $14(\mathrm{I} .8 \%)$ & $16(7 \%)$ & $16(7 \%)$ & $16(3 \%)$ & $16(3 \%)$ \\
\hline Sputum culture ${ }^{\dagger}$ & $16(2.4 \%)$ & $17(2.3 \%)$ & N.A. & N.A. & N.A. & N.A. \\
\hline Drugs & $46(7 \%)$ & $383(52 \%)$ & $46(18 \%)$ & $46(18 \%)$ & $46(9 \%)$ & $46(8 \%)$ \\
\hline X-rays ${ }^{\dagger}$ & $12(1.8 \%)$ & $11(1.5 \%)$ & N.A. & N.A. & N.A. & N.A. \\
\hline $\begin{array}{l}\text { Overall supervision of } \\
\text { community-based programme }\end{array}$ & N.A. & N.A. & $74(29 \%)$ & $72(28 \%)$ & N.A. & N.A. \\
\hline $\begin{array}{l}\text { Training for community } \\
\text { 'treatment supporters' }\end{array}$ & N.A. & N.A. & I (0.4\%) & $\mathrm{I}(0.4 \%)$ & N.A. & N.A. \\
\hline Total cost per patient & 654 & 744 & 251 & 253 & 507 & 568 \\
\hline \multicolumn{7}{|l|}{ Mean patient cost } \\
\hline \multicolumn{7}{|l|}{$\begin{array}{l}\text { Visits to clinic for monitoring } \\
\text { and DOT }\end{array}$} \\
\hline Travel cost & $\mathrm{N} / \mathrm{A}$ & N/A & $2.1(1.7-2.4)$ & $2.6(2.3-3.2)$ & $26.2(25.1-27.6)$ & $20.3(\mid 8.6-23.8)$ \\
\hline Time cost & N/A & N/A & $6.2(4.0-8.3)$ & $5.9(4.6-6.5)$ & $75.6(71.8-78.2)$ & $101.9(94.4-115.1)$ \\
\hline \multicolumn{7}{|l|}{$\begin{array}{l}\text { Visits to 'treatment } \\
\text { supporter' for DOT }\end{array}$} \\
\hline Travel cost & N/A & $N / A$ & 0 & 0 & N.A. & N.A. \\
\hline Time cost & $\mathrm{N} / \mathrm{A}$ & N/A & $30.9(23.6-36.8)$ & $28.2(24.9-30.5)$ & N.A. & N.A. \\
\hline Total cost per patient & $\mathrm{N} / \mathrm{A}$ & N/A & $39.2(28.3-47.5)$ & $36.7(31.8-40.2)$ & $101.8(96.9-105.8)$ & $122.2(113.0-138.9)$ \\
\hline \multicolumn{7}{|l|}{$\begin{array}{l}\text { Financing of treatment } \\
\text { cost }\end{array}$} \\
\hline Public provider & N.A. & N.A. & $59(20 \%)$ & $63(20 \%)$ & 445 (73\%) & $506(73 \%)$ \\
\hline Private provider & $609(93 \%)$ & $708(95 \%)$ & $121(42 \%)$ & $114(39 \%)$ & N.A. & N.A. \\
\hline Provincial TB programme $\ddagger$ & $46(7 \%)$ & $36(5 \%)$ & $71(24 \%)$ & $76(27 \%)$ & $62(10 \%)$ & $62(9 \%)$ \\
\hline Patient & N.A. & N.A. & $39(13 \%)$ & 37 (13\%) & $102(17 \%)$ & $122(18 \%)$ \\
\hline Total cost per patient & 654 & 744 & 290 & 290 & 609 & 690 \\
\hline
\end{tabular}

* Cost data from 200I. Average exchange rate prevailing in $200 \mathrm{I}$ US $\$ 1=\mathrm{R} 8.57$.

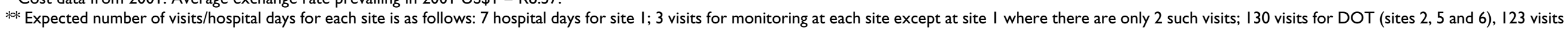
for DOT (site I), and I0 visits for DOT (sites 3 and 4); I 20 visits to 'treatment supporter' (sites 3 and 4).

† Expected number of diagnostic tests for each site: 4 sputum smears (site I), 7 sputum smears (site 2), and 4 sputum smears (sites $4-6$ ); I sputum culture (sites I and 2); 3 X-rays (sites I and 2).

†† N.A. = not applicable.

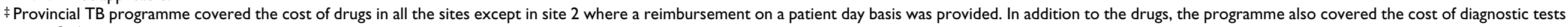
in sites 3-6. 
had the lowest cost per patient treated and was less than half of that found in the PWP model. DOT was the most significant cost in public clinics (84-85\%) and $40-51 \%$ of costs in PWP sites. The largest cost component for PNP was the overall supervision of the programme (28-29\%).

The cost to the patient in the purely public model was between 2.6 and 3.3 times higher than the PNP model reflecting less time that a patient had to spend getting the treatment in the community and lower transport cost (Table 3).

The costs of $\mathrm{TB}$ treatment were largely financed by the main provider in each site (Table 3). PWP providers financed $93-95 \%$ of the total cost with a small $5-7 \%$ contribution required from the provincial TB programme. In contrast, the provincial TB programme contributed 24$27 \%$ of financing towards PNP sites, with the public sector also paying for another $20 \%$ of costs. However, in budgetary terms this meant that the provincial TB programme contributed only up to twice the amount of funding to PNP sites as it did for PWP, reflecting the much lower cost per patient treated (\$290) in the PNP sites versus the public or PWP sites.

\section{Treatment outcomes}

Table 4 shows treatment outcomes for all new smear-positive cases in the cohort. The treatment success rate ranged between $74 \%$ (site 6 ) and $89 \%$ (site 5) and the cure rate ranged between $65 \%$ (site 3 ) and $87 \%$ (site 5 ). The major influence on effectiveness were high mortality rates of $12 \%$ and $11 \%$ in sites 1 and 2 respectively, and high defaulting rates of $24 \%$ and $16 \%$ (and so lower cure rates) in sites 3 and 6 respectively which were the only 2 urban sites. No one model performed unambiguously better than the others.

\section{Cost-effectiveness}

A provider-only perspective shows the most cost-effective TB treatment was the PNP model reflecting both lower cost per patient treated and relatively higher treatment success and cure rates (Table 4 ). The least cost-effective TB treatment was the PWP model, where sites achieved relatively higher successful treatment success and cure rates, but the average costs per patient treated were the highest.

From the patient's perspective, the most cost-effective TB treatment was the PWP model (TB treatment was workplace-based and the employer covered the cost of transport), followed by the PNP model (TB treatment was community-based and accessible to the patient). The least cost-effective was the purely public model, reflecting long waiting hours and poor geographical accessibility of public clinics. From the social perspective, the PNP model remained the most cost-effective model of all the models of provision. However, from a societal perspective, there were similar ranges for cost-effectiveness between the PWP model and the purely public model.

\section{Sensitivity analyses}

The results were robust in sensitivity analyses (Table 5) with cost and cost-effectiveness assumptions most sensitive to valuation of staff time. The relative rankings remained the same. Sensitivity analysis using the number of registered patients adjusted by the number of the patients who died during the treatment showed that results were not sensitive to plausible variability in the effectiveness data. Cost-effectiveness in the higher HIV prevalence sites improved considerably when compared to other study sites.

\section{Discussion}

This study provides evidence on the cost-effectiveness of different PPP models for the provision of TB treatment in South Africa. In the two PPP models, increased community involvement and availability of treatment at a workplace were more affordable to the public sector. The effectiveness was also better in the PPP models, suggesting that the public-private models of provision are more effective than the purely public model. This may be due to superior quality of care provided in public-private settings [25]. Overall, the PNP model was consistently the most cost-effective model, similar to results elsewhere evaluating community-based models [13-19]. However, these results are preliminary due to a limited number of sites available for each model and therefore cannot provide definite conclusions. The study is context-specific and exploratory in its nature as it evaluates exiting models and does not provide any definite results.

The new costs associated with the community-based treatment to the public sector were small in comparison with the cost of DOT in public clinics. The incentive paid to community treatment supporters (on average US\$ 0.3 per visit) was much lower than the average cost of a clinic visit (on average US\$ 3.5 per visit). The availability of the treatment at a workplace and in the community resulted in substantial savings to the patient. In addition to the cost reduction to the public sector, by providing $\mathrm{TB}$ treatment to poorer community members and employees, the treatment became more accessible and convenient for patients in both study populations reducing costs to the patient by $64 \%-100 \%$.

It is also important to consider where the employer-based and community-based approaches are of greatest relevance. Arguably, the employer-based TB treatment is most appropriate in companies which employ a large number of people, where occupational health clinics exist and where TB is an occupational health problem, as it is in the 
Table 4: Treatment outcome and cost-effectiveness (CE) for each model of treatment provision in 200 I US $\$ *$

\begin{tabular}{|c|c|c|c|c|c|c|}
\hline \multirow[t]{3}{*}{ Treatment outcome ${ }^{* *}$} & \multicolumn{2}{|c|}{ PWP model } & \multicolumn{2}{|c|}{ PNP model } & \multicolumn{2}{|c|}{ Purely public model } \\
\hline & Site I & Site 2 & Site 3 & Site 4 & Site 5 & Site 6 \\
\hline & $N=95$ & $N=423$ & $N=355$ & $N=50$ & $N=85$ & $N=174$ \\
\hline Successfully treated $t$ & $83(87 \%)$ & $368(87 \%)$ & $283(80 \%)$ & $4 \mid(82 \%)$ & $76(89 \%)$ & $129(74 \%)$ \\
\hline Curedtt & 79 (83\%) & $321(76 \%)$ & $231(65 \%)$ & 41 (82\%) & 74 (87\%) & $121(69 \%)$ \\
\hline Failed $\ddagger$ & I (I\%) & 4 (I\%) & $3(1 \%)$ & I (2\%) & 0 & I (I\%) \\
\hline Died抽 & $11(12 \%)$ & 47 (12\%) & $13(4 \%)$ & $4(8 \%)$ & I (I\%) & $4(2 \%)$ \\
\hline Interrupted $\S$ & - & - & $56(15 \%)$ & $4(8 \%)$ & $8(10 \%)$ & $40(23 \%)$ \\
\hline
\end{tabular}

\section{CE from the provider}

\section{perspective}

Total cost of treating patient

Treatment success rate§§

Cure ratell

Cost per new smear-positive

patient successfully treated

Cost per new smear-positive

patient cured

$\begin{array}{cc}654 & 744 \\ 87 & 87 \\ 83 & 76 \\ 752 & 855 \\ 788 & 979\end{array}$

$\begin{array}{cccc}744 & 251 & 253 & 507 \\ 87 & 80 & 82 & 89 \\ 76 & 65 & 82 & 87 \\ 855 & 314 & 308 & 570 \\ 979 & & \end{array}$

$507 \quad 568$

$89-74$

$\begin{array}{ll}87 & 69\end{array}$

570
767

\section{CE from the patient}

\section{perspective}

Total cost of treating patient

979

386

583

823

Treatment success rate

Cure rate

Cost per new smear-positive

patient successfully treated

Cost per new smear-positive

patient cured

\section{CE from the societal}

perspective

Total cost of treating patient

Treatment success rate

Cure rate

Cost per new smear-positive

patient successfully treated

Cost per new smear-positive

patient cured

$\begin{array}{ll}39 & 37 \\ 80 & 82 \\ 65 & 82 \\ 49 & 45 \\ 60 & 45\end{array}$

102

* Cost data from 200I. Average exchange rate prevailing in 200I US\$I = R8.57.

** Source: Reports submitted to the provincial TB programmes.

† The sum of those patients who were cured plus those who completed treatment but without laboratory proof of cure.

tt Patients who were smear negative at the end of treatment.

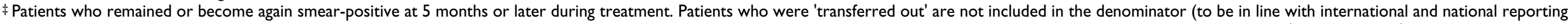

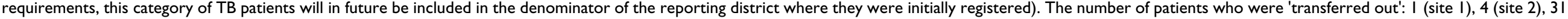
(site 3), 9 (site 4), 16 (site 5) and 35 (site 6).

¥ Patients who died for any reason during the course of TB treatment.

$\S$ Patients whose treatment was interrupted for 2 months or more

$\S \S$ Estimated as a ratio between the number of new smear-positive patients registered and the number of new smear-positive patients successfully treated.

$\|$ Estimated as a ratio between the number of new smear-positive patients registered and the number of new smear-positive patients cured.

|| IIThis represents a sum of provider and patient costs for each site. 


\section{Alternative estimates of provider costs (staff time)}

- \% divergence from base-case provider cost estimate

- \% divergence from base-case provider cost-effectiveness estimate

Lower limit patient cost

- \% divergence from base-case patient cost estimate

- \% divergence from base-case patient cost-effectiveness estimate

Upper limit patient cost

- \% divergence from base-case patient cost estimate

-\% divergence from base-case patient cost-effectiveness estimate

$0 \%$ discount rate

- \% divergence from base-case provider cost estimate

- \% divergence from provider cost-effectiveness estimate

$6 \%$ discount rate

- \% divergence from base-case provider cost estimate

-\% divergence from provider cost-effectiveness estimate

Effectiveness adjusted by the death rate**

-\% divergence from base-case treatment success rate

- \% divergence from base-case societal cost-effectiveness estimate (treatment

success rate)

- \% divergence from base-case cure rate

- \% divergence from base-case societal cost-effectiveness estimate (cure rate)

Multivariate analysis (estimates of provider cost and effectiveness

adjusted by the death rate are varied at the same time)

- \% divergence from base-case provider cost estimate

- \% divergence from base-case cure rate

- \% divergence from base-case societal cost-effectiveness estimate

\begin{tabular}{|c|c|c|c|c|c|}
\hline Site I & Site 2 & Site 3 & Site 4 & Site 5 & Site6 \\
\hline$-15 \%$ & $-13 \%$ & $-8 \%$ & $-8 \%$ & $-24 \%$ & $-28 \%$ \\
\hline$-15 \%$ & $-13 \%$ & $-8 \%$ & $-8 \%$ & $-24 \%$ & $-28 \%$ \\
\hline N.A.* & N.A. & $-5 \%$ & $-5 \%$ & $-5 \%$ & $-5 \%$ \\
\hline N.A. & N.A. & $-4 \%$ & $-3 \%$ & $-1 \%$ & $-1 \%$ \\
\hline N.A. & N.A. & $+5 \%$ & $+5 \%$ & $+5 \%$ & $+5 \%$ \\
\hline N.A. & N.A & $+3 \%$ & $+0.2 \%$ & $+0.6 \%$ & $+2 \%$ \\
\hline$-3 \%$ & $-3 \%$ & $-3 \%$ & $-3 \%$ & $-3 \%$ & $-3 \%$ \\
\hline$-2 \%$ & $-0.6 \%$ & $-0.5 \%$ & $-2 \%$ & $-1 \%$ & $-0.5 \%$ \\
\hline$+3 \%$ & $+3 \%$ & $+3 \%$ & $+3 \%$ & $+3 \%$ & $+3 \%$ \\
\hline$+3 \%$ & $+2 \%$ & $+2 \%$ & $+3 \%$ & $+2 \%$ & $+2 \%$ \\
\hline$-12 \%$ & $-11 \%$ & $-4 \%$ & $-8 \%$ & $-1 \%$ & $-2 \%$ \\
\hline$-12 \%$ & $-11 \%$ & $-4 \%$ & $-8 \%$ & $-1.6 \%$ & $-2.5 \%$ \\
\hline$-12 \%$ & $-11 \%$ & $-4 \%$ & $-8 \%$ & $-1 \%$ & $-2 \%$ \\
\hline$-12 \%$ & $-11 \%$ & $-4 \%$ & $-8 \%$ & $-1 \%$ & $-2 \%$ \\
\hline$-15 \%$ & $-13 \%$ & $-8 \%$ & $-8 \%$ & $-24 \%$ & $-28 \%$ \\
\hline$-12 \%$ & $-11 \%$ & $-4 \%$ & $-8 \%$ & $-1 \%$ & $-2 \%$ \\
\hline$-25 \%$ & $-23 \%$ & $-11 \%$ & $-15 \%$ & $-25 \%$ & $-30 \%$ \\
\hline
\end{tabular}

$*$ N.A. $=$ not applicable

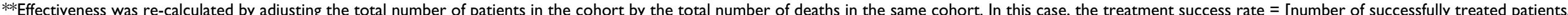
(total number of patients - number of patients who died during treatment) $] * 100$. For example, in site $\mathrm{I}$, the treatment success rate adjusted by the death rate $=[83 /(95-\mathrm{II})] * 100=99 \%$.

mining industry. In the case of the community-based TB treatment, it is most appropriate in areas where public sector clinics are already working at capacity; where clinic-based care is not achieving high cure rates; where geographical access to health facilities for patients is poor; and where more affordable but still cost-effective approaches are required due to health service budget cuts and/or increases in the number of TB cases. The different ways in which community-based TB treatment can be implemented depend on the level of socio-economic development, the degree of social mobilisation for TB among other health activities, and the particular cultural setting (Maher et al 1999). While the principles of community contribution of TB are generalisable (e.g. close links between the general health services, TB control programme and community-based NGOs), the details of how this model of service delivery is designed and implemented will depend largely on the specific setting.

The study has a number of limitations. Non-randomised purposive sampling was used to identify sites that reflected communities and locations where PPPs are currently in place. Thus the sites varied significantly in terms of TB incidence due to the nature of the PPP target groups. Although efforts were made to try and select sites with similar HIV prevalence rates, the nature of the PPP target groups and scarcity of data on HIV prevalence made this difficult. As there is a higher mortality rate for HIV+ TB patients, we were not able to control for the fact that TB treatment outcomes might have been poorer in sites with a higher HIV prevalence rate than in sites with a lower HIV prevalence rate. This could underestimate the cost-effectiveness at higher HIV/TB incidence sites. However, it is difficult to discuss the importance of HIV prevalence differences on the study results as HIV prevalence rates are based on estimates by the clinic staff. The study results might also be different if smear negative cases were selected. The PPPs were all relatively well functioning (with cure rates well above the South African average of 55\%). The purposive sampling may have led to identification of better-functioning PPPs, which may suggest that results are optimistic. The conventional practice of using average reported incomes among a sample of patients is used to value patient time. This might have under or overestimated true costs. Finally, whilst important, the time cost of identifying, selecting, initiating and sustaining different PPPs, and the "stewardship" costs, such as ensuring that the private partners follow TB treatment guidelines, to government were not included in 
the analysis. We estimate these costs to be around US $\$ 35,000$ per year per province (this is the salary cost of a middle-level manager whose main responsibility would be to manage PPPs for the provision of TB). In addition, a range of incentives should be used to encourage private sector participation in partnership with the government for the provision of TB treatment. While recognising that 'getting incentives right' is important in any principalagent relationship, monitoring and evaluation of the partnerships, however, may not always be easy and other factors, such as levels of trust and perceptions of relative risks, may potentially play an essential role in underpinning efficient public-private relationships.

\section{Conclusion}

Overall, the results suggest there is a strong economic case for expanding PPP involvement in TB treatment in the process of scaling up. The cost per new patient treated to government could be reduced by enhanced partnership between the private and public sectors. Expansion of PPPs could potentially lead to reduced government sector financing requirements for new patients: government financing would require \$609-690 per new patient treated, in contrast to PNP sites which would only need to \$130-139 per patient (almost a five-fold reduction in costs), and \$36-46 (a fifteen fold reduction) with the PWP model. The study models are comparable in that they follow the same TB treatment protocol, are similar in terms of key social, economic and demographic characteristics, and provide care to the lower-income populations. The major caveat to using the study results in making policy recommendations is that it was based on a small number of study sites. Whilst including such a small sample of sites should not have influenced losing any rigour, the results should be interpreted as preliminary.

Tuberculosis treatment provided through the PPPs also seems to be more accessible and convenient for patients in both study populations. Through partnership with the government, mining companies and community-based NGOs can take most of the responsibility for their own employees and associated communities respectively. The PWP model appears to be more sustainable than the PNP model, mainly due to dependency of the NGOs on external financing. Moreover, employers have an economic incentive to keep the workforce healthy.

This study evaluated different models of provision for different study populations. Ideally, an experiment should be set up to compare different models for the same population. In urban areas, both PNP and public sites had greater default rates. This may well improve by using PPPs involving other types of private providers such as private practitioners in urban areas. Currently these types of arrangements are limited relative to other parts of the world [26-28].

Expansion may require increased investment in the PPPs, but they seem to be capable of delivering important improvements in the affordability and efficiency of TB treatment, and improving the South African health system's capacity to cope with the impact of the HIV/AIDS epidemic. Regardless of the model, the provincial TB programmes had to finance some proportion of the total cost per patient (although almost 50\% lower for PWP models). Managing PPPs, however, is challenging as they embody a complex set of relationships between public and private actors and require careful monitoring [8]. These findings could also be applicable to PPPs in the provision of other services such STI treatment [29] and reproductive health services [30]. PPPs should be seen as complementary to public services as the different models serve different target groups. These results show that where PPPs are tailored to the context and well-supported by the public sector, scaling-up of effective services could occur at much lower cost relative to solely scaling up traditional public sector models. However, an assessment of the resources required from the government for training, monitoring and quality control of PPPs is crucial, and further research into financial sustainability of the NGOs is needed.

\section{Competing interests}

The author(s) declare that they have no competing interests.

\section{Authors' contributions}

ES designed, planned and carried out the study, wrote the manuscript and interpreted the data. LK participated in the design of the study and helped draft the manuscript. Both authors read and approved the final manuscript.

\section{Acknowledgements}

We thank the officials of the Department of Health, the mining companies, and the NGOs who gave generously of their time, information and expertise. Lilani Kumaranayake is a member of the UK-DFID funded LSHTM TB and HIVIAIDS\&STI programmes.

The UNDP/World Bank/WHO Special Programme for Research and Training in Tropical Diseases (TDR) provided funds for this study.

\section{References}

I. Stop TB Partnership and WHO: Global plan to stop TB 2006201 5. Geneva: World Health Organisation; 2006.

2. Elzinga G, Raviglione MC, Maher D: Scale-up: meeting targets in global tuberculosis control. The Lancet 2004, 363:8|4-19.

3. Uplekar M: Private health care. Social Science and Medicine 2000, I I :897-904.

4. Uplekar M, Pathania V, Raviglione M: Private practitioners and public health: weak Links in tuberculosis control. The Lancet 2001, 385:912-16.

5. Hurtig AK, Pande SB, Baral SC, Porter JDH, Bam DS: Anti-tuberculosis treatment in private pharmacies, Kathmandu Valley, 
Nepal. International Journal of Tuberculosis and Lung Disease 2000, 4(8):730-736

6. Gilson L, Mills A: Health sector reforms in sub-Saharan Africa: Lessons of the last 10 years. In Health sector reform in developing countries: making health development sustainable Edited by: Berman P. Boston: Harvard University Press; 1995.

7. Reich MR: Public-private partnerships for public health. Nature Medicine 2000, 6:617-620.

8. Uplekar M: Involving private health care providers in delivery of TB care: global strategy. Tuberculosis 2003, 83:156-164.

9. Mills A, Brugha R, Hanson K, McPake B: What can be done about the private health sector in low-income countries? Bulletin of the World Health Organisation 2002, 80(4):325-330.

10. National Department of Health: The health act. Pretoria: Republic of South Africa; 1997.

II. National Department of Health: Policy framework on public-private interactions. Pretoria: Republic of South Africa; 2001.

12. Khan MA, Walley JD, Witter SN, Imran A, Safdar N: Cost and costeffectiveness of different DOT strategies for the treatment of tuberculosis in Pakistan - directly observed treatment. Health Policy and Planning 2002, 17:178-186.

13. Islam A, Wakai S, Ishikawa N, Chowdhury AMR, Vaughan JP: Costeffectiveness of community-health workers in tuberculosis control in Bangladesh. Bulletin of the World Health Organisation 2002, 80(6):445-450.

14. Nganda B, Wang'ombe J, Floyd K, Kangangi J: Cost and cost-effectiveness of Increased community and primary care facility involvement in tuberculosis care in Machakos District, Kenya. International Journal of Tuberculosis and Lung Disease 2003, 7(Suppl 9): | 4-20.

15. Floyd K, Skeva J, Nyirenda T, Gausi F, Salaniponi F: Cost and costeffectiveness of increased community and primary care facility involvement in TB care in Lilongwe District, Malawi. International Journal of Tuberculosis and Lung Disease 2003, 7(Supp 9):29-37.

16. Sinanovic E, Floyd K, Dudley L, Azevedo V, Grant R, Maher D: Cost and cost effectiveness of community-based care for tuberculosis in Cape Town, South Africa. International Journal of Tuberculosis and Lung Disease 2003, 7(Suppl 9):56-62.

17. Okello D, Floyd K, Adatu F, Odeke R, Gargioni G: Cost and costeffectiveness of community-based care in rural Uganda. International Journal of Tuberculosis and Lung Disease 2003, 7(Suppl 9):80-85.

18. Moalosi G, Floyd K, Phatshwane J, Moeti T, Binkin N, Kenyon T: Cost-effectiveness of home-based care versus hospital care for chronically ill tuberculosis patients, Francistown, Botswana. International Journal of Tuberculosis and Lung Disease 2003, 7(Suppl 9):80-85.

19. Floyd K, Arora VK, Murthy KJR, Lonnroth K, Singla N, Akbar Y, Zingol M, Uplekar M: Cost and cost-effectiveness of public and private sector collaboration in tuberculosis control: evidence from India. Bulletin of the World Health Organisation in press.

20. World Health Organisation: Global tuberculosis control report 2006. Geneva: World Health Organisation; 2006.

21. Dorrington RE, Bradshaw D, Budlender D: HIVIAIDS profile of the provinces in South Africa - indicators for 2002. Centre for Actuarial Research, Medical Research Council and the Actuarial Society of South Africa 2002.

22. Department of Health: The South African tuberculosis control programme practical guidelines. Pretoria: National Department of Health; 2000 .

23. Murray CJL, Evans DB, Acharya A, Baltussen RMPM: Development of WHO Guidelines on generalized cost-effectiveness analysis. Health Economics 2000, 9:235-5I.

24. Russell LB, Gold MR, Siegel JE, Daniels N, Weinstein MC: The role of cost effectiveness analysis in health and medicine. Journal of American Medical Association 1996, 276: I 172-79.

25. Sinanovic E, Kumaranayake L: Quality of tuberculosis care provided in different models of public-private partnerships in South Africa. International Journal of Tuberculosis and Lung Disease in press.

26. Newell JN, Pande SB, Baral SC, Bam DS, Malla P: Control of tuberculosis in an urban setting in Nepal: public-private partnership. Bulletin of the World Health Organisation 2004, 82(2):92-98.

27. Quy HT, Lan NTN, Lonnroth K, Buu TN, Dieu TTN, Hai LT: Publicprivate mix for improved TB control in Ho Chi Minh City,
Vietnam: an assessment of its impact on case detection. International Journal of Tuberculosis and Lung Disease 2003, 7(5):464-47I.

28. Murthy KJR, Frieden TR, Yazdani A, Hreshikesh P: Public-private partnership in tuberculosis control: experience in Hyderabad, India. International Journal of Tuberculosis and Lung Disease 200I, 5(4):354-359.

29. Palmer N, Mills A, Wadee H, Gilson H, Schneider $\mathrm{H}$ : A new face for private providers In developing countries: what implications for public health? Bulletin of the World Health Organisation 2003, 8 I (4):292-297

30. Brugha R, Pritze-Aliassime S: Promoting safe motherhood through the private sector In low- and middle-income countries. Bulletin of the World Health Organisation 2003, 8 I (8):6। 6-622.

Publish with Bio Med Central and every scientist can read your work free of charge

"BioMed Central will be the most significant development for disseminating the results of biomedical research in our lifetime. "

Sir Paul Nurse, Cancer Research UK

Your research papers will be:

- available free of charge to the entire biomedical community

- peer reviewed and published immediately upon acceptance

- cited in PubMed and archived on PubMed Central

- yours - you keep the copyright
BioMedcentral 